\title{
Da redistribuição ao reconhecimento? Dilemas da justiça numa era "pós-socialista"
}

\author{
Nancy Fraser \\ TRADUÇão: Julio Assis Simótes
}

A “luta por reconhecimento" está rapidamente se tornando a forma paradigmática de conflito político no final do século XX. Demandas por "reconhecimento da diferença" dão combustível às lutas de grupos mobilizados sob as bandeiras da nacionalidade, etnicidade, "raça", gênero e sexualidade. Nestes conflitos "pós-socialistas", a identidade de grupo suplanta o interesse de classe como o meio principal da mobilização política. A dominaçáo cultural suplanta a exploração como a injustiça fundamental. E o reconhecimento cultural toma o lugar da redistribuição socioeconômica como remédio para a injustiça e objetivo da luta política.

Claro que esta não é toda a história. Lutas pelo reconhecimento ocorrem num mundo de exacerbada desigualdade material - desigualdades de renda e propriedade; de acesso a trabalho remunerado, educação, saúde e lazer; e também, mais cruamente, de ingestão calórica e exposição à contaminação ambiental; portanto, de expectativa de vida e de taxas de morbidade e mortalidade. A desigualdade material está em alta na maioria dos países do mundo - nos EUA e na China, na Suécia e na Índia, na Rússia e no Brasil. Ela também aumenta globalmente, de modo mais dramático, do outro lado da linha que divide norte e sul.

Como, então, devemos ver o eclipse de um imaginário socialista centrado em termos como "interesse", "exploração" e "redistribuiçãa”? E o que devemos fazer com a emergência de um novo imaginário político centrado nas noçóes de "identidade", "diferença", "dominação cul- tural" e "reconhecimento"? Essa virada representa um lapso de "falsa consciência"? Ou seria mais um meio de compensar a cegueira cultural de um paradigma marxista posto em descrédito pelo colapso do comunismo soviético?

Nenhuma das duas posiçóes é adequada, a meu ver. Ambas são demasiado abrangentes e sem nuanças. Ao invés de simplesmente endossar ou rejeitar o que é simplório na política da identidade, devíamos nos dar conta de que temos pela frente uma nova tarefa intelectual e prática: a de desenvolver uma teoria crítica do reconhecimento, que identifique e assuma a defesa somente daquelas versóes da política cultural da diferença que possam ser combinadas coerentemente com a política social da igualdade.

Ao formular esse projeto, assumo que a justiça hoje exige tanto redistribuição como reconhecimento. E proponho examinar a relação entre eles. Isso significa, em parte, pensar em como conceituar reconhecimento cultural e igualdade social de forma a que sustentem um ao outro, ao invés de se aniquilarem (pois há muitas concepçóes concorrentes de ambos!) Significa também teorizar a respeito dos meios pelos quais a privação econômica e o desrespeito cultural se entrelaçam e sustentam simultaneamente. Exige também, portanto, esclarecer os dilemas políticos que surgem quando tentamos combater as duas injustiças ao mesmo tempo.

Meu objetivo maior é ligar duas problemáticas políticas atualmente dissociadas; pois é 
somente integrando reconhecimento e redistribuição que chegaremos a um quadro conceitual adequado às demandas de nossa era.

\section{[...]}

Para ajudar a esclarecer esta situação e as perspectivas políticas que ela apresenta, proponho distinguir analiticamente duas maneiras muito genéricas de compreender a injustiça. A primeira delas é a injustiça econômica, que se radica na estrutura econômico-política da sociedade. Seus exemplos incluem a exploração (ser expropriado do fruto do próprio trabalho em benefício de outros); a marginalização econômica (ser obrigado a um trabalho indesejável e mal pago, como também não ter acesso a trabalho remunerado); e a privação (não ter acesso a um padrão de vida material adequado).

Teóricos igualitários empreenderam grande esforço para conceituar a natureza dessas injustiças socioeconômicas. Suas concepçóes incluem a teoria de Marx sobre a exploraçáo capitalista; a concepçáo de justiça de Rawls, como justiça na seleçáo dos princípios que regem a distribuição dos "bens primários"; a visão de Amartya Sen, de que justiça implica "capacidades de função" iguais; e a de Ronald Dworkin, de que justiça implica "igualdade de recursos”. Para meus propósitos neste trabalho, porém, não precisamos nos comprometer com nenhuma visão teórica em particular. Precisamos apenas subscrever uma compreensão geral e rudimentar da injustiça socioeconômica informada por um compromisso com o igualitarismo.

A segunda maneira de compreender a injustiça é cultural ou simbólica. Aqui a injustiça se radica nos padróes sociais de representação, interpretação e comunicação. Seus exemplos incluem a dominação cultural (ser submetido a padróes de interpretação e comunicação associados a outra cultura, alheios e/ou hostis à sua própria); o ocultamento (tornar-se invisível por efeito das práticas comunicativas, interpretativas e representacionais autorizadas da própria cultura); e o desrespeito (ser difamado ou desqualificado rotineiramente nas representaçóes culturais públicas estereotipadas e/ou nas interaçóes da vida cotidiana).

\section{[...]}

Insistirei em distinguir analiticamente injustiça econômica e injustiça cultural, em que pese seu mútuo entrelaçamento. $\mathrm{O}$ remédio para a injustiça econômica é alguma espécie de reestruturação político-econômica. Pode envolver redistribuição de renda, reorganização da divisão do trabalho, controles democráticos do investimento ou a transformação de outras estruturas econômicas básicas. Embora esses vários remédios difiram significativamente entre si, doravante vou me referir a todo esse grupo pelo termo genérico "redistribuição". O remédio para a injustiça cultural, em contraste, é alguma espécie de mudança cultural ou simbólica. Pode envolver a revalorização das identidades desrespeitadas e dos produtos culturais dos grupos difamados. Pode envolver, também, o reconhecimento e a valorização positiva da diversidade cultural. Mais radicalmente ainda, pode envolver uma transformação abrangente dos padróes sociais de representação, interpretação e comunicação, de modo a transformar o sentido do eu de todas as pessoas. Embora esses remédios difiram significativamente entre si, doravante vou me referir a todo esse grupo pelo termo genérico "reconhecimento".

\section{[...]}

Postas estas distinçóes, posso passar agora à questão seguinte: qual é a relação entre lutas por reconhecimento, voltadas para remediar a injustiça cultural, e lutas por redistribuição, voltadas para compensar a injustiça econômica? E que espécie de interferências mútuas podem brotar quando os dois tipos de reivindicação são feitos simultaneamente?

Existem boas razóes para se preocupar com essas interferências mútuas. Lutas de 
reconhecimento assumem com freqüência a forma de chamar a atenção para a presumida especificidade de algum grupo - ou mesmo de criá-la performativamente - e, portanto, afirmar seu valor. Desse modo, elas tendem a promover a diferenciação do grupo. Lutas de redistribuição, em contraste, buscam com freqüência abolir os arranjos econômicos que embasam a especificidade do grupo (um exemplo seriam as demandas feministas para abolir a divisão do trabalho segundo o gênero). Desse modo, elas tendem a promover a desdiferenciação do grupo. O resultado é que a política do reconhecimento e a política da redistribuição parecem ter com freqüência objetivos mutuamente contraditórios. Enquanto a primeira tende a promover a diferenciação do grupo, a segunda tende a desestabilizá-la. Desse modo, os dois tipos de luta estão em tensão; um pode interferir no outro, ou mesmo agir contra o outro.

Eis, então, um difícil dilema. Doravante vou chamá-lo dilema da redistribuição-reconhecimento. Pessoas sujeitas à injustiça cultural e à injustiça econômica necessitam de reconhecimento e redistribuição. Necessitam de ambos para reivindicar e negar sua especificidade. Como isso é possível?

\section{[...]}

As coisas são bem claras nas duas extremidades de nosso espectro conceitual. Quando lidamos com coletividades que se aproximam do tipo ideal da classe trabalhadora explorada, encaramos injustiças distributivas que precisam de remédios redistributivos. Quando lidamos com coletividades que se aproximam do tipo ideal da sexualidade desprezada, em contraste, encaramos injustiças de discriminação negativa que precisam de remédios de reconhecimento. No primeiro caso, a lógica do remédio é acabar com esse negócio de grupo; no segundo caso, ao contrário, trata-se de valorizar o "sentido de grupo" do grupo, reconhecendo sua especificidade.
As coisas ficam mais turvas, porém, à medida que nos afastamos das extremidades. Quando consideramos coletividades localizadas na região intermediária do espectro conceitual, encontramos tipos híbridos que combinam características da classe explorada com características da sexualidade desprezada. Essas coletividades são "bivalentes". São diferenciadas como coletividades tanto em virtude da estrutura econômico-política quanto da estrutura cultural-valorativa da sociedade. Oprimidas ou subordinadas, portanto, sofrem injustiças que remontam simultaneamente à economia política e à cultura. Coletividades bivalentes, em suma, podem sofrer da má distribuição socioeconômica e da desconsideração cultural de forma que nenhuma dessas injustiças seja um efeito indireto da outra, mas ambas primárias e co-originais. Nesse caso, nem os remédios de redistribuição nem os de reconhecimento, por si sós, são suficientes. Coletividades bivalentes necessitam dos dois.

Gênero e "raça" são paradigmas de coletividades bivalentes. Embora cada qual tenha peculiaridades náo compartilhadas pela outra, ambas abarcam dimensóes econômicas e dimensóes cultural-valorativas. Gênero e "raça", portanto, implicam tanto redistribuiçáo quanto reconhecimento.

O gênero, por exemplo, tem dimensóes econômico-políticas porque é um princípio estruturante básico da economia política. Por um lado, o gênero estrutura a divisão fundamental entre trabalho "produtivo" remunerado e trabalho "reprodutivo" e doméstico não-remunerado, atribuindo às mulheres a responsabilidade primordial por este último. Por outro lado, o gênero também estrutura a divisão interna ao trabalho remunerado entre as ocupaçóes profissionais e manufatureiras de remuneração mais alta, em que predominam os homens, e ocupaçóes de "colarinho rosa" e de serviços domésticos, de baixa remuneração, 
em que predominam as mulheres. $\mathrm{O}$ resultado é uma estrutura econômico-política que engendra modos de exploração, marginalização e privação especificamente marcados pelo gênero. Esta estrutura constitui o gênero como uma diferenciação econômico-política dotada de certas características da classe. Sob esse aspecto, a injustiça de gênero aparece como uma espécie de injustiça distributiva que clama por compensaçóes redistributivas. De modo muito semelhante à classe, a injustiça de gênero exige a transformação da economia política para que se elimine a estruturaçáo de gênero desta. Para eliminar a exploração, marginalização e privação especificamente marcadas pelo gênero é preciso abolir a divisão do trabalho segundo ele - a divisão de gênero entre trabalho remunerado e não-remunerado e dentro do trabalho remunerado. A lógica do remédio é semelhante à lógica relativa à classe: trata-se de acabar com esse negócio de gênero. Se o gênero não é nada mais do que uma diferenciação econômicopolítica, a justiça exige, em suma, que ele seja abolido.

Isso, no entanto, é apenas uma parte da história. $\mathrm{Na}$ verdade, o gênero não é somente uma diferenciação econômico-política, mas também uma diferenciação de valoração cultural. Como tal, ele também abarca elementos que se assemelham mais à sexualidade do que à classe, e isso permite enquadrá-lo na problemática do reconhecimento. Seguramente, uma característica central da injustiça de gênero é o androcentrismo: a construção autorizada de normas que privilegiam os traços associados à masculinidade. Em sua companhia está o sexismo cultural: a desqualificação generalizada das coisas codificadas como "femininas", paradigmaticamente - mas não só -, as mulheres. Essa desvalorização se expressa numa variedade de danos sofridos pelas mulheres, incluindo a violência e a exploração sexual, a violência doméstica generalizada; as representaçóes ba- nalizantes, objetificadoras e humilhantes na mídia; o assédio e a desqualificação em todas as esferas da vida cotidiana; a sujeição às normas androcêntricas, que fazem com que as mulheres pareçam inferiores ou desviantes e que contribuem para mantê-las em desvantagem, mesmo na ausência de qualquer intenção de discriminar; a discriminação atitudinal; a exclusão ou marginalização das esferas públicas e centros de decisão; e a negação de direitos legais plenos e proteçóes igualitárias. Esses danos são injustiças de reconhecimento. São relativamente independentes da economia política e não são meramente "superestruturais". Por isso, não podem ser remediados apenas pela redistribuição econômico-política, mas precisam de medidas independentes e adicionais de reconhecimento. $\mathrm{O}$ androcentrismo e sexismo predominantes exigem a mudança dos valores culturais (assim como de suas expressóes legais e práticas) que privilegiam a masculinidade e negam respeito às mulheres. Exigem o descentramento das normas androcêntricas e a revalorização de um gênero desprezado. A lógica do remédio é semelhante à lógica relativa à sexualidade: conceder reconhecimento positivo a um grupo especificamente desvalorizado.

O gênero é, em suma, um modo bivalente de coletividade. Ele contém uma face de economia política, que o insere no âmbito da redistribuição. Mas também uma face cultural-valorativa, que simultaneamente o insere no âmbito do reconhecimento. Naturalmente, as duas faces não são claramente separadas uma da outra. Elas se entrelaçam para se reforçarem entre si dialeticamente porque as normas culturais sexistas e androcêntricas estáo institucionalizadas no Estado e na economia e a desvantagem econômica das mulheres restringe a "voz" das mulheres, impedindo a participação igualitária na formação da cultura, nas esferas públicas e na vida cotidiana. O resultado é um círculo vicioso de subordinação cultural e econômica. Para compensar a 
injustiça de gênero, portanto, é preciso mudar a economia política e a cultura.

Mas o caráter bivalente do gênero é a fonte de um dilema. Uma vez que as mulheres sofrem, no mínimo, de dois tipos de injustiça analiticamente distintos, elas necessariamente precisam, no mínimo, de dois tipos de remédios analiticamente distintos: redistribuição e reconhecimento. Os dois remédios pendem para direçóes opostas, porém, e não é fácil persegui-las ao mesmo tempo. Enquanto a lógica da redistribuição é acabar com esse negócio de gênero, a lógica do reconhecimento é valorizar a especificidade de gênero. Eis, então, a versão feminista do dilema da redistribuição-reconhecimento: como as feministas podem lutar ao mesmo tempo para abolir a diferenciaçáo de gênero e para valorizar a especificidade de gênero?

Um dilema análogo aparece na luta contra o racismo. A "raça", como o gênero, é um modo bivalente de coletividade. Por um lado, ela se assemelha à classe, sendo um princípio estrutural da economia política. Neste aspecto, a "raça" estrutura a divisão capitalista do trabalho. Ela estrutura a divisão dentro do trabalho remunerado, entre as ocupaçóes de baixa remuneração, baixo status, enfadonhas, sujas e domésticas, mantidas desproporcionalmente pelas pessoas de cor, e as ocupaçóes de remuneração mais elevada, de maior status, de "colarinho branco", profissionais, técnicas e gerenciais, mantidas desproporcionalmente pelos "brancos". A divisáo racial contemporânea do trabalho remunerado faz parte do legado histórico do colonialismo e da escravidáo, que elaborou categorizaçóes raciais para justificar formas novas e brutais de apropriação e exploraçáo, constituindo efetivamente os "negros" como uma casta econômico-política. Atualmente, além disso, a "raça" também estrutura o acesso ao mercado de trabalho formal, constituindo vastos segmentos da populaçáo de cor como subploretariado ou subclasse, degradado e "supérfluo" que não vale a pena ser explorado e é totalmente excluído do sistema produtivo. O resultado é uma estrutura econômico-política que engendra modos de exploração, marginalização e privação especificamente marcados pela "raça". Essa estrutura constitui a raça como uma diferenciação econômico-política dotada de certas características de classe. Sob esse aspecto, a injustiça racial aparece como uma espécie de injustiça distributiva que clama por compensaçóes redistributivas. De modo muito semelhante à classe, a injustiça racial exige a transformação da economia política para que se elimine a racialização desta. Para eliminar a exploração, marginalização e privação especificamente marcadas pela "raça" é preciso abolir a divisão racial do trabalho - a divisão racial entre trabalho explorável e supérfluo e a divisão racial dentro do trabalho remunerado. A lógica do remédio é semelhante à lógica relativa à classe: trata-se de fazer com que a "raça" fique fora do negócio. Se a "raça" não é nada mais do que uma diferenciaçáo econômico-política, a justiça exige, em suma, que ela seja abolida.

Entretanto, a raça, como o gênero, não é somente econômico-política. Ela também tem dimensóes culturais-valorativas, que a inserem no universo do reconhecimento. Assim, a "raça" também abarca elementos mais parecidos com a sexualidade do que com a classe. Um aspecto central do racismo é o eurocentrismo: a construçáo autorizada de normas que privilegiam os traços associados com o "ser branco". Em sua companhia está o racismo cultural: a desqualificaçáo generalizada das coisas codificadas como "negras", "pardas" e "amarelas", paradigmaticamente - mas não só - as pessoas de cor. Esta depreciação se expressa numa variedade de danos sofridos pelas pessoas de cor, incluindo representações estereotipadas e humilhantes na mídia, como criminosos, brutais, primitivos, estúpidos etc; violência, assédio e difamação 
em todas as esferas da vida cotidiana; sujeição às normas eurocêntricas que fazem com que as pessoas de cor pareçam inferiores ou desviantes e que contribuem para mantê-las em desvantagem mesmo na ausência de qualquer intenção de discriminar; a discriminação atitudinal; a exclusão e/ou marginalização das esferas públicas e centros de decisão; e a negação de direitos legais plenos e proteçóes igualitárias. Como no caso do gênero, esses danos são injustiças de reconhecimento. Por isso, a lógica do remédio também é conceder reconhecimento positivo a um grupo especificamente desvalorizado.

A “raça” também é, portanto, um modo bivalente de coletividade com uma face econômico-política e uma face cultural-valorativa. Suas duas faces se entrelaçam para se reforçarem uma à outra, dialeticamente, ainda mais porque as normas culturais racistas e eurocêntricas estão institucionalizadas no Estado e na economia, e a desvantagem econômica sofrida pelas pessoas de cor restringe sua "voz". Para compensar a injustiça racial, portanto, é preciso mudar a economia política e a cultura. Mas, como ocorre com o gênero, o caráter bivalente da "raça" é a fonte de um dilema. Uma vez que as pessoas de cor sofrem, no mínimo, de dois tipos de injustiça analiticamente distintos, elas necessariamente precisam, no mínimo, de dois tipos de remédios analiticamente distintos: redistribuição e reconhecimento, que náo são facilmente conciliáveis. Enquanto a lógica da redistribuição é acabar com esse negócio de "raça", a lógica do reconhecimento é valorizar a especificidade do grupo. Eis, então, a versão anti-racista do dilema da redistribuição-reconhecimento: como os anti-racistas podem lutar ao mesmo tempo para abolir a "raça" e para valorizar a especificidade cultural dos grupos racializados subordinados?

Gênero e "raça" são, em suma, modos dilemáticos de coletividade. Diferentemente da classe, que ocupa uma das extremidades do espectro conceitual, e da sexualidade, que ocupa a outra, gênero e "raça" são bivalentes, implicados ao mesmo tempo na política de redistribuição e na política do reconhecimento. Ambos, conseqüentemente, enfrentam o dilema da redistribuição-reconhecimento. As feministas devem buscar remédios que dissolvam a diferenciação de gênero, enquanto buscam também remédios culturais que valorizem a especificidade de uma coletividade desprezada. Os anti-racistas, da mesma maneira, devem buscar remédios econômico-políticos que dissolvam a diferenciação "racial", enquanto buscam também remédios culturais que valorizem a especificidade de coletividades desprezadas. Como podem fazer as duas coisas ao mesmo tempo?

Até aqui, apresentei o dilema da redistribuição-reconhecimento de uma forma que parece completamente intratável. Assumi que os remédios redistributivos para a injustiça econômico-política sempre diferenciam os grupos sociais. Da mesma maneira, assumi que os remédios de reconhecimento para a injustiça cultural-valorativa sempre realçam a diferenciação do grupo social. Diante dessas posições, é difícil ver como feministas e anti-racistas podem buscar redistribuição e reconhecimento ao mesmo tempo.

Agora, porém, quero complicar essas posições. Nesta seção, vou examinar concepções alternativas de redistribuição, de um lado, e concepçóes alternativas de reconhecimento, de outro. Meu objetivo é distinguir duas grandes abordagens para corrigir a injustiça que atravessam o divisor da redistribuição-reconhecimento. Vou chamá-las de "afirmação" e "transformação”, respectivamente. Após apresentá-las genericamente, mostrarei como cada uma opera em relação à redistribuição e ao reconhecimento. Por fim, a partir dessa base, vou reformular o dilema da redistribuição-reconhecimento para uma forma mais aberta a uma resolução. 
Vou começar por uma breve distinção entre afirmação e transformação. Por remédios afirmativos para a injustiça, entendo os remédios voltados para corrigir efeitos desiguais de arranjos sociais sem abalar a estrutura subjacente que os engendra. Por remédios transformativos, em contraste, entendo os remédios voltados para corrigir efeitos desiguais precisamente por meio da remodelação da estrutura gerativa subjacente. O ponto crucial do contraste é efeitos terminais vs. processos que os produzem - e náo mudança gradual $v$ s. mudança apocalíptica.

Pode-se aplicar essa distinção, primeiramente, aos remédios para a injustiça cultural. Remédios afirmativos para tais injustiças são presentemente associados ao que vou chamar "multiculturalismo mainstream". Essa espécie de multiculturalismo propóe compensar o desrespeito por meio da revalorização das identidades grupais injustamente desvalorizadas, enquanto deixa intactos os conteúdos dessas identidades e as diferenciaçóes grupais subjacentes a elas. Remédios transformativos, em contraste, são presentemente associados à desconstrução. Eles compensariam o desrespeito por meio da transformaçáo da estrutura cultural-valorativa subjacente. Desestabilizando as identidades e diferenciaçóes grupais existentes, esses remédios não somente elevariam a autoestima dos membros de grupos presentemente desrespeitados; eles transformariam o sentido do eu de todos.

Para ilustrar a distinção, vamos considerar, mais uma vez, o caso da sexualidade desprezada. Remédios afirmativos para a homofobia e o heterossexismo sáo presentemente associados com a política de identidade gay, que visa a revalorizar a identidade gay e lésbica. Remédios transformativos, em contraste, são associados à política queer, que se propóe a desconstruir a dicotomia homo-hétero. A política de identidade gay trata a homossexualidade como uma positividade cultural, com seu próprio conteú- do substantivo, muito semelhante à etnicidade (ou à visão de senso comum desta). Assume-se que essa positividade subsiste em si e de si mesma, necessitando somente de reconhecimento adicional. A política queer, em contraste, trata a homossexualidade como um correlato construído e desvalorizado da heterossexualidade; ambas são reificaçóes da ambigüidade sexual e são co-definidas somente uma em relaçáo à outra. O objetivo transformativo não é consolidar uma identidade gay, mas desconstruir a dicotomia homo-hétero de modo a desestabilizar todas as identidades sexuais fixas. A questão não é dissolver toda a diferença sexual numa identidade humana única e universal; mas sim manter um campo sexual de diferenças múltiplas, não-binárias, fluidas, sempre em movimento.

As duas abordagens são de considerável interesse como remédios para a ausência de reconhecimento. Mas há uma diferença considerável entre elas. Enquanto a política de identidade gay tende a realçar a diferenciação de grupo sexual existente, a política queer tende a desestabilizá-la - no mínimo, ostensivamente e no longo prazo. A observação vale para os remédios de reconhecimento, de modo geral. Enquanto os remédios de reconhecimento afirmativos tendem a promover as diferenciaçóes de grupo existentes, os remédios de reconhecimento transformativos tendem, no longo prazo, a desestabilizá-las, a fim de abrir espaço para futuros reagrupamentos.

[...]

Distinções análogas valem para os remédios para a injustiça econômica. Os remédios afirmativos para essas injustiças estão associados historicamente ao Estado de bem-estar liberal. Eles buscam compensar a má distribuição terminal, enquanto deixam intacta a maior parte da estrutura econômico-política subjacente. Assim, eles aumentariam a parte de consumo dos grupos economicamente desprivilegiados, sem 
reestruturar o sistema de produção. Remédios transformativos, em contraste, são associados historicamente ao socialismo. Eles compensariam a distribuição injusta transformando a estrutura econômico-política existente. Reestruturando as relaçóes de produção, esses remédios não somente alterariam a distribuição terminal das partes de consumo; mudariam também a divisão social do trabalho e, assim, as condiçóes de existência de todos.

Para ilustrar a distinção, vamos considerar, mais uma vez, o caso da classe explorada. Remédios de redistribuição afirmativos para as injustiças de classe freqüentemente incluem transferências de renda de dois tipos distintos: programas de seguro social dividem parte dos custos de reproduçáo social dos empregados formais, os chamados setores primários da classe trabalhadora; programas de assistência pública oferecem auxílios "focalizados" ao "exército de reserva" de desempregados e subempregados. Longe de abolirem a divisão de classes per $s e$, esses remédios afirmativos sustentam-na $\mathrm{e}$ moldam-na. Seu efeito geral é desviar a atençáo da divisão de classes entre trabalhadores e capitalistas para a divisão entre as fraçóes empregadas e desempregadas da classe trabalhadora. Programas de assistência pública "focalizam" os pobres não só por auxílio, mas por hostilidade. Tais remédios, com certeza, oferecem a ajuda material necessitada. Mas também criam diferenciaçóes de grupo fortemente antagônicas.

A lógica aqui se aplica à redistribuição afirmativa em geral. Embora essa abordagem vise a compensar a injustiça econômica, ela deixa intactas as estruturas profundas que engendram a desvantagem de classe. Assim, é obrigada a fazer realocaçóes superficiais constantemente. O resultado é marcar a classe mais desprivilegiada como inerentemente deficiente e insaciável, sempre necessitando mais e mais. Com o tempo essa classe pode mesmo aparecer como privilegiada, recebedora de tratamento especial e generosidade imerecida. Assim, uma abordagem voltada para compensar injustiças de distribuição pode acabar criando injustiças de reconhecimento.

Em certo sentido, esta abordagem é internamente contraditória. A redistribuição afirmativa, em geral, pressupóe uma concepçáo universalista de reconhecimento, a igualdade de valor moral das pessoas. Vamos chamar isso seu "compromisso formal de reconhecimento". Entretanto, a prática da redistribuição afirmativa, reiterada ao longo do tempo, tende a pôr em movimento uma dinâmica secundária de reconhecimento estigmatizante, que contradiz seu compromisso formal com o universalismo. Essa dinâmica secundária, estigmatizante, pode ser entendida como o "efeito de reconhecimento prático" da redistribuição afirmativa.

Vamos, agora, contrastar essa lógica com os remédios transformativos para as injustiças distributivas de classe. Remédios transformativos comumente combinam programas universalistas de bem-estar social, impostos elevados, políticas macroeconômicas voltadas para criar pleno emprego, um vasto setor público nãomercantil, propriedades públicas e/ou coletivas significativas, e decisóes democráticas quanto às prioridades socioeconômicas básicas. Eles procuram garantir a todos o acesso ao emprego, enquanto tendem também a desvincular a parte básica de consumo e o emprego. Logo, sua tendência é dissolver a diferenciação de classe. Remédios transformativos reduzem a desigualdade social, porém sem criar classes estigmatizadas de pessoas vulneráveis vistas como beneficiárias de uma generosidade especial. Eles tendem, portanto, a promover reciprocidade e solidariedade nas relaçóes de reconhecimento. Assim, uma abordagem voltada a compensar injustiças de distribuição pode ajudar também a compensar (algumas) injustiças de reconhecimento. 
Essa abordagem é internamente consistente. Como a redistribuição afirmativa, a redistribuição transformativa em geral pressupóe uma concepção universalista de reconhecimento, a igualdade de valor moral das pessoas. Diferente da redistribuição afirmativa, contudo, sua prática tende a não dissolver essa concepção. Assim, as duas abordagens engendram diferentes lógicas de diferenciação de grupo. Enquanto os remédios afirmativos podem ter o efeito perverso de promover a diferenciaçáo de classe, os remédios transformativos tendem a embaçala. Além disso, as duas abordagens engendram diferentes dinâmicas subliminares de reconhecimento. A redistribuição afirmativa pode estigmatizar os desprivilegiados, acrescentando o insulto do menosprezo à injúria da privação. A redistribuição transformativa, em contraste, pode promover a solidariedade, ajudando a compensar algumas formas de náo-reconhecimento.

$\mathrm{O}$ que devemos concluir, pois, desta discussão? Nesta seção, consideramos somente os casos típico-ideais "puros" nas duas extremida- des do espectro conceitual. Contrastamos os efeitos divergentes dos remédios afirmativos e transformativos para as injustiças distributivas de classe, enraizadas economicamente, de um lado, e para as injustiças de reconhecimento da sexualidade, enraizadas culturalmente, de outro. Vimos que remédios afirmativos tendem, em geral, a promover a diferenciação de grupo, enquanto remédios transformativos tendem a desestabilizá-la ou embaçá-la. Vimos também que os remédios de redistribuição afirmativos podem engendrar um protesto de menosprezo, enquanto os remédios de redistribuição transformativos podem ajudar a compensar algumas formas de não-reconhecimento.

Tudo isso sugere um meio de reformular o dilema da redistribuição-reconhecimento. A pergunta que pode ficar é: no que diz respeito aos grupos submetidos aos dois tipos de injustiças, qual será combinação de remédios que funciona melhor para minimizar, senão para eliminar de vez, as interferências mútuas que surgem quando se busca redistribuição e reconhecimento ao mesmo tempo?

\title{
traduzido de
}

FRASER, Nancy. 2001. "From redistribution to recognition? Dilemmas of justice in a 'postsocialist' age”. In: S. Seidman; J. Alexander. (orgs.). 2001. The new social theory reader. Londres: Routledge, pp. 285-293.

Outra versão do artigo foi publicada na New Left Review (212: 68-93, 1995).

\author{
tradutor Julio Assis Simóes \\ Professor do Departamento de Antropologia / USP
}

Recebido em 30/09/2006

Aceito para publicação em 30/11/2006 